\title{
Fire development in different scales of train carriages
}

\author{
YING ZHEN LI, HAUKUR INGASON and ANDERS LÖNNERMARK \\ Fire Technology \\ SP Technical Research Institute of Sweden \\ Box 857, SE-501 15 Borås, Sweden
}

\begin{abstract}
A fire development analysis of three series of train carriage fire tests in different scales was carried out. These train carriage fire tests included 1:10 model scale tests, 1:3 model scale tests and 1:1 full scale tunnel tests. The heat release rate (HRR) correlations between different scales of carriage fire tests were carefully investigated. The mechanism of fire development is very similar in different scales of tests involving fully developed fires. After the critical fire spread, the fire travelled along the carriage at an approximately constant speed. The maximum heat release rate obtained for a fully developed fire is dependent on the ventilation conditions and also the type and configuration of the fuels, and a simple equation has been proposed to estimate the maximum heat release rate. A global correction factor of the maximum heat release rate is presented and examined.
\end{abstract}

KEYWORDS: train carriage fire, different scales, correlation, fire tests, fire development, local flashover, maximum heat release rate.

\section{NOMENCLATURE LISTING}

$\begin{array}{llll}A_{f} & \text { fuel surface area }\left(\mathrm{m}^{2}\right) & t & \text { time }(\mathrm{s}) \\ A_{i} & \text { ith exposed surface area }\left(\mathrm{m}^{2}\right) & T & \text { Gas temperature }(\mathrm{K}) \\ A_{o} & \text { area of opening }\left(\mathrm{m}^{2}\right) & u & \text { velocity }(\mathrm{m} / \mathrm{s}) \\ A_{t} & \text { total exposed surface area }\left(\mathrm{m}^{2}\right) & \mathbf{G r e e k} & \\ c_{p} & \text { heat capacity }(\mathrm{kJ} / \mathrm{kg} \cdot \mathrm{K}) & \rho & \text { density }\left(\mathrm{kg} / \mathrm{m}^{3}\right) \\ E & \text { energy content }(\mathrm{kJ}) & \xi_{i} & \text { correction factor for } i \text { th surface } \\ \text { Fr } & \text { Froude number } & \xi_{\text {tot }} & \text { global correction factor } \\ H & \text { carriage height }(\mathrm{m}) & \chi_{r} & \text { fraction of heat absorbed by surfaces } \\ H_{o} & \text { height of opening }(\mathrm{m}) & \text { subscripts } \\ \Delta H_{c} & \text { effective heat of combustion }(\mathrm{kJ} / \mathrm{kg}) & c & \text { convection heat transfer } \\ l & \text { length scale }(\mathrm{m}) & c a l & \text { calculated } \\ L_{p} & \text { heat of pyrolysis }(\mathrm{kJ} / \mathrm{kg}) & f & \text { fuel } \\ m & \text { fuel mass }(\mathrm{kg}) & F & \text { full scale } \\ \dot{m}_{a} & \text { mass flow rate of the fresh air }(\mathrm{kg} / \mathrm{s}) & g & \text { gas } \\ \dot{m}_{f} & \text { fuel mass burning rate }(\mathrm{kg} / \mathrm{s}) & i & \text { ith opening or } i \text { th surface } \\ \dot{m}^{\prime \prime} & \text { mass burning rate per unit area }\left(\mathrm{kg} / \mathrm{m}^{2} \cdot \mathrm{s}\right) & M & \text { model scale } \\ Q & \text { heat release rate }(\mathrm{MW}) & \text { max } & \text { maximum } \\ Q_{m a x} & \text { maximum heat release rate }(\mathrm{MW}) & \text { meas } & \text { measured } \\ Q_{i n} & \text { maximum heat release rate in carriage }(\mathrm{MW}) & o & \text { opening or initial value } \\ \dot{q}_{e}^{\prime \prime} & \text { absorbed external heat flux }\left(\mathrm{kW} / \mathrm{m}^{2}\right) & \text { stoi } & \text { stoichiometric } \\ \dot{q}_{l o s s}^{\prime \prime} & \text { heat loss from the surface }\left(\mathrm{kW} / \mathrm{m}^{2}\right) & \text { total }\end{array}$




\section{INTRODUCTION}

The development of underground transportation systems is a necessity to facilitate the transportation in urban areas. Fires in these systems could not only potentially cost human lives and injuries, but also result in significant costs in economical terms. The need for research on fire development in such train carriage fires is clear.

Full scale fire tests are the best way to obtain valuable information about the realistic carriage fires. However, the huge cost and the resulting limited number of tests make a parametric study impossible. Instead, model scale tests can be used to study parametric dependencies in greater detail.

In the framework of the METRO project, a three-year Swedish research project on fire safety in rail mass transport systems [1], different scales of train carriage fire tests have been carried out [2-6]. The objective of the present work is to identify the correlations between different scales of train carriage fire test in relation to the fire development and HRR. The train carriages analysed were from fire tests including 1:10 model scale tests, 1:3 model scale tests and 1:1 full scale tunnel tests. The underlying focus in this study is on development of design fires (HRR) and the related phenomenon in different scales of train carriage fires.

\section{SCALING}

The widely used Froude scaling is applied in the presented work. While using scale modelling it is important to define the similarity between the full scale and the model scale well. A complete similarity involves for example both gas flow conditions and the effect of material properties. The gas flow conditions can be described by a number of non-dimensional groups, e.g. the Froude number, the Reynolds number, and the Richardson number. For perfect scaling, all of these groups should be the same in the model-scale model as in the full-scale case. This is, however, typically impossible due to some conflicting requirements and it is often sufficient to conserve the primary groups especially the Froude number:

$$
\mathrm{Fr}=\frac{u^{2}}{g l}
$$

where $u$ is the velocity scale, $g$ is the acceleration of gravity, and $l$ is the length scale. The scaling laws of the main parameters in Froude scaling used in this study are presented in Table 1. The Reynolds number is not conserved in the different scales. Previous studies by the authors have, however, proved that model-scale studies can give interesting results and give important information on fire behaviours under different conditions [7-15].

Table 1. A list of scaling correlations for the train carriage tests.

\begin{tabular}{|l|c|c|}
\hline Type of unit & Scaling & Equation \\
\hline Heat Release Rate (HRR) (MW) & $\dot{Q}_{M} / \dot{Q}_{F}=\left(l_{M} / l_{F}\right)^{5 / 2}$ & $(2)$ \\
\hline Temperature (K) & $T_{M} / T_{F}=1$ & $(3)$ \\
\hline Velocity (m/s) & $u_{M} / u_{F}=\left(l_{M} / l_{F}\right)^{1 / 2}$ \\
\hline Time (s) & $t_{M} / t_{F}=\left(l_{M} / l_{F}\right)^{1 / 2}$ & $(5)$ \\
\hline Mass (kg) & $m_{M} / m_{F}=\left(\Delta H_{c, F} / \Delta H_{c, M}\right)\left(l_{M} / l_{F}\right)^{3}$ & $(6)$ \\
\hline Fuel mass burning rate $\left(\mathrm{kg} / \mathrm{m}^{2} \mathrm{~s}\right)$ & $\dot{m}_{f, M}^{\prime \prime} / \dot{m}_{f, F}^{\prime \prime}=\left(\Delta H_{c, F} / \Delta H_{c, M}\right)\left(l_{M} / l_{F}\right)^{1 / 2}$ & $(7)$ \\
\hline Fuel density $\left(\mathrm{kg} / \mathrm{m}^{3}\right)$ & $\rho_{f, M} / \rho_{f, F}=\Delta H_{c, F} / \Delta H_{c, M}$ & $(8)$ \\
\hline
\end{tabular}

In the 1:3 model scale tests [3], the scaling ratio is 1:3, which could indicate that keeping the same material may not result in significant difference in the tests data. Therefore, materials similar to those used in full scale were used. The materials used were scaled geometrically according to the length scale. The total energy 
content was also scaled. For the seats in 1:3 model scale, the exterior coverings were removed which could somewhat reduce the ignition time for the seats. The test results, however, indicate that the quality of polyurethane used in the 1:3 model scale tests made the seats behave in a similar way as in real scale when it comes to ignition and fire spread.

In the 1:10 model scale tests [2], simple fuel configuration was applied. The main fuels were the combustible linings attached to the ceiling, floor and walls. These linings are more combustible compared to the linings used in carriages in reality. In addition, two wood cribs were placed on the floor to simulate the seats and luggage. Therefore, the scaling laws are only partly conserved in these tests.

\section{THEORETICAL MODEL}

A fully developed fire can either be ventilation controlled or fuel controlled. For fuel controlled fires, the total heat release rate can be estimated based on the exposed fuel surface areas using the following equation:

$$
Q_{\max }=\sum_{i} \dot{m}_{f, i}^{\prime \prime} A_{f, i} \Delta H_{c, i}
$$

For a ventilation controlled fire, besides the combustion inside a carriage, the combustion could also occur outside the openings, and the heat release rate is not only related to the ventilation factor, but also the fuels available in the carriages. This part of external flame could play an important role in the fire spread to other carriages.

For full scale carriages, the estimated maximum heat release rate based on the exposed fuel surfaces is around 95 MW. For 1:3 model scale tests, the estimated maximum heat release rate is approximately of the same value as in the full scale; but for 1:10 model scale tests, the maximum heat release rate is around $170 \mathrm{MW}$ in full scale. The full scale data suggest that in typical train carriages, the total heat release rates estimated based on the exposed fuel surface areas are much higher than the heat release rates obtained from the tests. Therefore, in the following we will focus on the ventilation controlled fires. However, a correction will be made to account for fuel controlled fires at the end of this section.

Firstly, we try to estimate the combustion that occurred inside the carriage. Note that the mass flow rate of the fresh air flow or the smoke flow for a ventilation controlled fire could be estimated using:

$$
\dot{m}_{a}=0.5 \sum_{i} A_{o, i} H_{o, i}^{1 / 2}
$$

If all the oxygen flowing into the compartment is consumed in the combustion inside the carriage, then the maximum HRR inside a compartment could be estimated by:

$$
\dot{Q}_{\text {max,in,stoi }}=3 \dot{m}_{a}
$$

where $\dot{Q}_{\text {max }}$ is the total heat release rate in MW, $\dot{m}_{a}$ the total mass flow rate through the openings $(\mathrm{kg} / \mathrm{s}), A_{o, i}$ and $H_{o, i}$ are the area and height of $i$ th opening respectively.

The total heat release rate, including both the combustion inside the carriage and outside of the carriage, could be estimated using Eq. (11) multiplied by a correction factor of the maximum heat release rate:

$$
\dot{Q}_{\max }=3 \xi \dot{m}_{a}
$$

In reality, this correction factor partly indicates how much combustible gas is released but not burnt inside the carriage.

Further, we need to check whether the oxygen inside the carriage could be consumed completely. 
The experiments in the different scales show that the gas temperatures inside the carriages were around 1000 ${ }^{\circ} \mathrm{C}$. Therefore, the maximum possible convective HRR in the compartment could be estimated by:

$$
\dot{Q}_{i n, c}=\dot{m}_{a} c_{p} \Delta T_{\max }
$$

where $\Delta T_{\max }=1000{ }^{\circ} \mathrm{C}$ and the corresponding $c_{p}=1.2$ (taking into account the high gas temperature). Generally the fraction of radiation in the total heat release rate is around $20 \%$ to $40 \%$ of the total heat release rate, although it depends on the type of linings, structures and physical openings such as doors or windows. In our case, $35 \%$ was assumed given that a large amount of heat was lost through the doors and openings. Therefore, we obtain the possible maximum HRR inside the carriage, i.e. excluding the energy release outside the openings using:

$$
\dot{Q}_{\max , \text { in }}=1.85 \dot{m}_{a}
$$

If the influence of the fuel mass rate is accounted for, the increase of the fuel mass flow rate results in a slight decrease of the mass flow rate into the carriage. The influence of the fuel mass on the total outgoing mass flow rate is limited and has been neglected.

Note that the possible HRR is lower than the maximum HRR. The possible HRR has a factor of 1.85 instead of 3 on the right-hand sides of the equations. This indicates that on average around $62 \%$ of the oxygen could be consumed inside the compartment. This value is estimated assuming that $Q_{c}$ is around $65 \%$ of the total heat release rate inside the carriage. In carriage fires, part of the heat is lost by radiation through the broken windows and open doors. We may estimate the radiation loss through openings from our full scale tests, which is around 4.3 MW for the carriage assuming an emissivity of 0.9. Further, note that using Eq. (14) the maximum heat release rate inside the carriage is estimated to be $35 \mathrm{MW}$, which indicates that around $12 \%$ of the heat release rate inside the train carriage was lost by radiation through the openings, of which approximately $50 \%$ was from the windows. Note that the radiation loss through the openings along the carriage for a post-flashover fire could be assumed to be uniformly distributed. In the early estimation of heat released inside the carriage, this part of the radiation loss has been taken into account when estimating the possible heat release rate inside the carriage. Therefore, this indicates the radiation to the other part of the carriage has been lowered down to around $23 \%$ (35\% minus $12 \%$ ). As a first approximation, this value will be used to estimate the fuel burning rate in the following.

To estimate the total heat release rate from the carriage, i.e. both inside and outside the carriage, the correction factor, $\xi$, of the maximum heat release rate needs to be known. Comparing the estimated maximum heat release rates based on the total exposed fuel surfaces with the measured values in these tests indicates that for a typical fully developed carriage fire the maximum heat release rate should be mainly dependent on the heat absorbed by the fuel surfaces. Therefore, in the following analysis, it is reasonable to assume that enough fuels in individual parts are available, and the heat absorbed by the fuel surface determines the heat release rate.

For fully developed carriage fires, the radiation dominates the heat transfer to the fuel surfaces. Further, the radiation level is approximately of the same value for all the fuel surfaces since the whole carriage is approximately in a homogenous environment. Therefore, the total heat absorbed by the fuels is mainly related to the exposed fuel surfaces.

The global energy balance equation could be simply expressed as:

$$
\dot{Q}_{\max }=\sum_{i} \dot{m}_{f, i} \Delta H_{c, i}=1.85 \dot{m}_{a} \sum_{i} \frac{\chi_{r, i} \Delta H_{c, i}}{L_{p, i}}
$$

The fraction of heat absorbed by the $i$ th surface, $\chi_{r, i}$, in the above equation is defined as: 
$\chi_{r, i}=\chi_{r} \frac{A_{i}}{A_{t}}$

Equating Eq. (12) and Eq. (15) for the maximum heat release rate, we have:

$$
\dot{Q}_{\max }=3 \xi_{t o t} \dot{m}_{a}=\sum_{i} 3 \xi_{i} \dot{m}_{a}=1.85 \dot{m}_{a} \sum_{i} \frac{\chi_{r, i} \Delta H_{c, i}}{L_{p, i}}
$$

This suggests the correction factor for the $i$ th fuel type, $\xi_{i}$, can be expressed as:

$\xi_{i}=\frac{\chi_{r, i} \Delta H_{c, i}}{L_{p, i}}$

where $\chi_{r}$ is the fraction of heat absorbed by the fuel surfaces in the total energy released inside the carriage, $\chi_{r, i}$ is the fraction of heat absorbed by the $i$ th fuel surfaces $A_{i}, L_{p}$ is heat of pyrolysis, $A_{i}$ is the $i$ th surface area and $A_{t}$ is the total surface areas exposed to the internal flame and it is the sum of individual surface area $A_{i}$. The total surface area includes all fuel surfaces and interior wall surfaces. The physical meaning of the fraction $\chi_{r, i}$ is the heat from the combustion flame inside the carriage which is absorbed by the $i$ th fuel surface. The fraction of heat absorbed by the $i$ th fuel surfaces could be zero at some location where no fuel is left, e.g. a wall fully covered by insulating materials. Further, note that from the previous analysis, the total fraction of heat absorbed by the fuel surfaces, $\chi_{r}$, has been preliminarily determined as 0.23 .

The fraction, $\chi_{r}$, is a key parameter to determine the correction factor of the heat release rate. Note that it is mainly related to the gas temperature inside the carriage, and the fuel configuration inside the carriage. The gas temperature inside the carriage has been found to be a constant at $1000^{\circ} \mathrm{C}$ in the tests in different scales. This fraction, $\chi_{r}$, should be close to the radiation fraction of the heat released inside the carriage since for fully developed fires all the surfaces were exposed to the heat. From the point of view of a global energy balance, this could be equated to the total radiation fraction minus the fraction lost through openings, that is, it should be around 0.23 . Further, the fuel configuration inside the carriage is quite similar between different scales. Therefore, the fraction, $\chi_{r}$, could be assumed to be constant for the train carriages. The value of 0.23 will be explored in the following using the tests data.

Clearly, the correction factor of the maximum heat release rate in a train carriage is mainly related to the type and configuration of the fuels, the effective heat of combustion and the heat of pyrolysis. It can be expected that for fire retardant materials, the correction factor should be lower.

Note that the above equations are obtained assuming that enough fuels in individual parts are available. Generally the assumption works well, but we may also need to check it for individual fuels. To account for fuel controlled fires, a simple correction is made here. For individual fuel parts, the minimum heat release rate, estimated based on the heat absorption analysis and fuel surface area, should be used as the heat release rate for each fuel type, which can be expressed as:

$$
\dot{Q}_{\max }=\sum_{i} \min \left(1.85 \dot{m}_{a} \frac{\chi_{r, i} \Delta H_{c, i}}{L_{p, i}}, \dot{m}_{f, \max , i}^{\prime \prime} A_{f, i} \Delta H_{c, i}\right)
$$

This is the general form of the equation for estimation of the maximum heat release rate in a fully developed train carriage fire or a similar enclosure fire. Based on Eq. (19) we could easily obtain the maximum heat release rates. The global correction factor of the maximum heat release rate can therefore be estimated using:

$$
\xi_{t o t}=\frac{\dot{Q}_{\max }}{3 \dot{m}_{a}}
$$


It has been shown that although these types of fires are normally called ventilation controlled fires, they are also closely related to the type and configuration of the fuels inside the carriage, i.e. in some way also fuel controlled as much of the combustion process occurs outside the carriage openings.

The maximum heat release rate in a specific carriage fire could be either fuel controlled or ventilation controlled, although in most cases the carriage fire is ventilation controlled according to traditional definitions. The general equation Eq. (19) is recommended for use in estimation of the maximum heat release rate in a train carriage fire or a similar enclosure fire.

\section{SUMMARY OF TESTS IN DIFFERENT SCALES}

Three series of train carriage fire tests were carried out in different scales according to the Froude scaling which has been further developed by SP. These tests include 1:10 model scale tests [2], 1:3 model scale tests [3], and full scale tunnel tests [1, 5-6]. In the following, a short description of these tests is presented.

\section{1:10 model scale railcar tests}

The test set-up consisted of a 1:10 geometrically similar scale model of a Swedish passenger railcar of type $\mathrm{X} 2000$ [2]. The train model was $2.44 \mathrm{~m}$ long, $0.3 \mathrm{~m}$ wide and $0.27 \mathrm{~m}$ high, placed above a weighing platform, see Fig. 1. The corresponding dimensions were $24.4 \mathrm{~m}$ long, $3 \mathrm{~m}$ wide and $2.7 \mathrm{~m}$ high at full scale. The model was constructed using non-combustible, $12 \mathrm{~mm}$ thick, boards (Promatect $\mathrm{H}$ ). There were nine windows on each side and each window was $0.15 \mathrm{~m}$ wide and $0.065 \mathrm{~m}$ high. One door was placed at one end of the carriage, with a geometry of $0.11 \mathrm{~m}(\mathrm{~W}) \times 0.23 \mathrm{~m}(\mathrm{H})$.

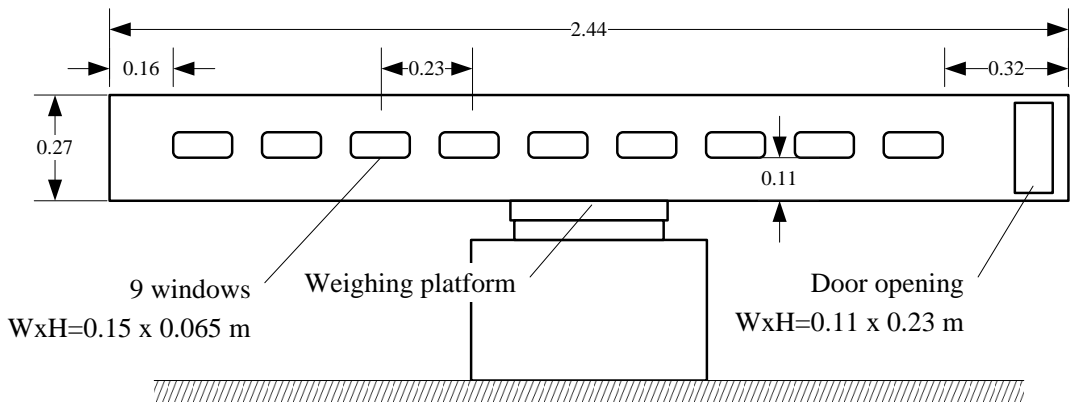

Fig. 1. A schematic diagram of the 1:10 model scale train carriage fire tests (dimensions in $\mathrm{m}$ ).

In total, five tests were performed with different initiation and test conditions. In principal two parameters were varied between the tests. Firstly, two different interior surface materials, i.e. plywood (tests 1 and 2) and corrugated cardboard (tests 3 to 5), were used on the ceiling, on the floor and on the walls. Secondly, during the tests, different numbers of windows were opened. These windows were opened when the fire visually started to decelerate, which means that they were not opened at a predetermined time. This procedure was chosen in order to make sure that the effects of the window openings were measurable in the gas exhaust system. During each test, two arrays of wood cribs were placed on the floor level to simulate the seats.

Beside the HRR measured above in a laboratory hood connected to the exhaust system, the temperature was measured with thermocouples (TCs) in the centre of the railcar and at 5 different levels from the floor: $0.03 \mathrm{~m}$ (TC5), $0.08 \mathrm{~m}$ (TC4), $0.135 \mathrm{~m}$ (TC3), $0.19 \mathrm{~m}$ (TC2), and $0.24 \mathrm{~m}$ (TC1). An additional four TCs were located at the highest level, $0.24 \mathrm{~m}$, evenly distributed along the ceiling, TC6-TC9. An exhaust pipe for gas sampling $\left(\mathrm{O}_{2}, \mathrm{CO}_{2}, \mathrm{CO}\right)$ was placed in the centre at level $0.24 \mathrm{~m}$ from the floor. At floor level in the centre of the railcar, a water cooled heat flux meter of type Schmidt-Boelter was placed.

\section{1:3 model scale railcar tests}

A total of 10 tests were carried out [3]. The model scale railcar was $7.27 \mathrm{~m}$ long, $1 \mathrm{~m}$ wide and $0.77 \mathrm{~m}$ high, and was built in the large fire hall at SP, see Fig. 2. The corresponding dimensions were $21.8 \mathrm{~m}$ long, $3 \mathrm{~m}$ wide and $2.3 \mathrm{~m}$ high at full scale, simulating the train carriage actually used in the full scale tests. The height of the railcar floor above the fire hall floor was $0.9 \mathrm{~m}$. 
In tests 5 and test 10, the fuels consisted of seats, combustible lining materials and long wood cribs placed on floor simulating the luggage. The only difference was that in test 5 three doors on one side were open and in test 10 all the six doors were open, three on each side.

Beside the HRR measured by oxygen consumption calorimetry, the gas temperature was measured using welded $0.25 \mathrm{~mm}$ type $\mathrm{K}$ thermocouples. Seven thermocouple trees were used with thermocouples at heights of $0.092 \mathrm{~m}, 0.23 \mathrm{~m}, 0.383 \mathrm{~m}, 0.537 \mathrm{~m}, 0.675 \mathrm{~m}$, to measure the vertical temperature distribution inside the railcar. The thermocouple trees were placed along the centerline of the model railcar at $(x) 0.305 \mathrm{~m}, 1.445 \mathrm{~m}$, $2.25 \mathrm{~m}, 2.54 \mathrm{~m}, 3.635 \mathrm{~m}, 5.825 \mathrm{~m}$ and $6.965 \mathrm{~m}$ away from the edge where ignition took place in most of the tests. Gas concentrations $\left(\mathrm{CO}_{2}\right.$ and $\left.\mathrm{CO}\right)$, were measured at the centre line of the railcar, at $\mathrm{x}=2.54 \mathrm{~m}$, at heights of $0.092 \mathrm{~m}, 0.383 \mathrm{~m}$ and $0.675 \mathrm{~m}$ above the floor. In addition, $\mathrm{O}_{2}$ was also measured at the same location and at heights of $0.383 \mathrm{~m}$ and $0.675 \mathrm{~m}$ above the floor. Heat fluxes outside the railcar were measured using plate thermometers. Different fire loads, openings and fire sources were tested. All three right hand doors (as seen from the ignition source), i.e. DR1, DR2 and DR3, were open during most of the tests.

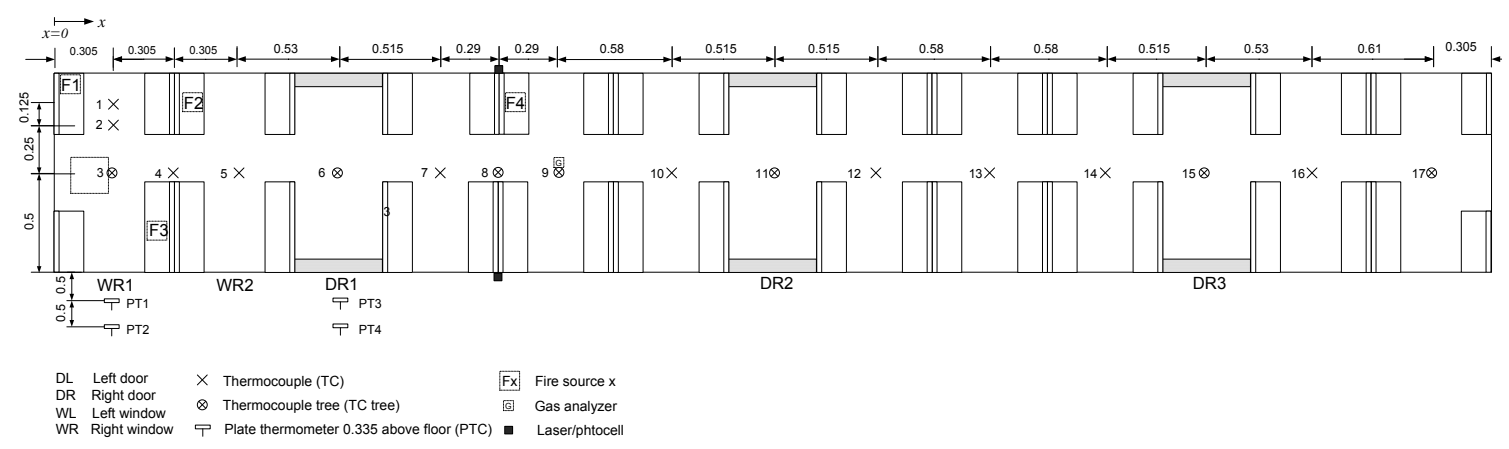

Fig. 2. A schematic diagram of the 1:3 model scale train carriage fire tests (plan view, dimensions in $\mathrm{m}$ ).

\section{1:1 full scale railcar tests}

The full scale tests were performed in the old Brunsberg tunnel, located between Kil and Arvika in western Sweden [1,5-6]. This abandoned, $276 \mathrm{~m}$ long tunnel lies on an about $1 \mathrm{~km}$ long siding. It was taken out of service when a new tunnel was constructed close by to reduce the sharpness of a bend in the route.

The cross-section of the tunnel varies along the tunnel and to obtain a better view of this variation, the cross-section was registered at 21 different positions along the tunnel. The tunnel height varied in these measurements between $6.7 \mathrm{~m}$ and $7.3 \mathrm{~m}$ with an average of $6.9 \mathrm{~m}$.

A total of 3 tests were carried out including one pool fire test 1 and two train carriage fire tests 2 and 3 . The trains used in the full scale carriage fire tests were the template for the 1:3 model scale tests, with the exception that the driver's compartment was included in the full scale tests, see Fig. 3. In test 2, an X1 train was used. In test 3, a refurbished X1 train, simulating a modern C20 train, was used. The interior walls and ceilings were fully covered by aluminium sheets and also some screens beside the doors were installed. Furthermore, the seats were changed to more modern ones.

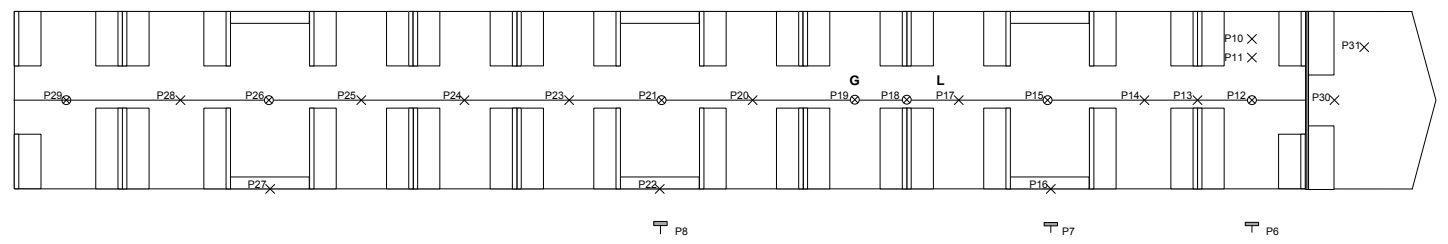

Fig. 3. A schematic diagram of the full scale carriage fire tests (plan view, dimensions in $\mathrm{m}$ ).

The total fire load of the train excluding the luggage and the locomotive was estimated to be 35.4 GJ. The estimation is based on information on walls, ceiling, floor and seats. Cables, etc. are not included in the estimation. In total 79 pieces of luggage were used with an average mass of $4.44 \mathrm{~kg}$ and a total mass of $351 \mathrm{~kg}$. If an average energy content of $20 \mathrm{MJ} / \mathrm{kg}$ is assumed the extra fire load corresponds to $7.2 \mathrm{GJ}$, which 
represents $17 \%$ of the new total fire load (42.6 GJ). The HRR was measured downstream of the tunnel flow at an instrument station measuring mass flow rates of oxygen, $\mathrm{CO}_{2}$ and $\mathrm{CO}$ together with gas temperatures.

\section{A short summary of the tests}

A summary of basic information about the test set-ups is given in Table 2. In the 1:10 tests, the train carriage was slightly longer and higher compared to the other geometries, and there was only one door open. Furthermore, the windows were smaller and opened manually when the fire visually started to decelerate, which means that they were not opened at a predetermined time. Therefore, the model carriage roughly scales to the carriage used in full scale tests. In the 1:3 model scale tests, the passenger carriage was scaled strictly in accordance to the carriage used in the full scale Brunsberg tunnel fire tests (1:1). However, the breakage of the windows did not scale well since that breakage is dependent on the size and configuration of the windows, and the temperature difference between interior and exterior sides of the windows.

Table 2. Summary of test set-up.

\begin{tabular}{|c|c|c|c|c|c|}
\hline \multirow{2}{*}{ Test series } & \multirow{2}{*}{ Number of tests } & \multicolumn{2}{|c|}{ Train geometry (model size) } & \multirow{2}{*}{$\begin{array}{c}\text { Openings } \\
\text { Available }\end{array}$} \\
\cline { 3 - 5 } & & length & width & height & \\
\hline & & $\mathrm{m}$ & $\mathrm{m}$ & $\mathrm{m}$ & \\
\hline $1: 10$ model scale & 5 & $24.4(2.44)$ & $3(0.3)$ & $2.7(0.27)$ & 1door, 18 windows \\
\hline $1: 3$ model scale & 10 & $21.8(7.26)$ & $3(1)$ & $2.31(0.77)$ & 3 or 6 doors \\
\hline $1: 1$ full scale & 2 & $21.8^{*}$ & 3 & 2.32 & 6 doors and 20 windows \\
\hline
\end{tabular}

*total length is approximately $24 \mathrm{~m}$ including the driver's cabin.

\section{RESULTS AND DISCUSSION}

Comparison of the results from these carriage fire tests in different scales is presented here, including fire development, maximum heat release rates and correction factor of the heat release rate.

\section{Fire development}

Note that in a train or metro carriage, the different pieces of combustible material are in most cases located separate from each other with the exception of the linings on the ceiling, walls and floor. Although the fire could spread along the linings by the mechanism of surface spread, the combustible material near the ignition source is limited, e.g. the linings are quite thin, especially in modern trains with fire retardant linings. Still it was shown in several of the tests that the ignition source could have a significant effect on the initial fire spread and thereby also the further development of the fire.

The main mechanism of the fire spread related to a fully developed fire is heat radiation from the ceiling hot gas layer. This mechanism is responsible for the flashover in a room fire. However, the scenario in a carriage is quite different, due to the fact that the carriage is long and the ceiling temperature decreases significantly along the distance away from the ignition source or the initial fire location before full flashover, if the ignition source is located close to one end of the carriage. This results in much lower radiation from the hot layer for a target far away from the initial fire location. Consequently, the full concept of flashover is not meaningful at the early stage of the fire before the fire becomes fully developed in the carriage.

Instead, the conception of a local flashover, defined as the state when the fire is fully developed within a zone, is more useful in the analysis of the fire development in the growth period. The fire spreads to the neighbouring fuels and becomes fully developed at the initial fire location. Then the initial local flashover is spread further which results in local flashover in more regions, and finally the whole carriage is involved which could be called a full flashover in the carriage. This behaviour can be described as a travelling fire.

The mechanisms of fire development in all the tests were found to be very similar. The spread of the fire from the initial location strongly depends on the fuels adjacent to the fire source. Examples of fuels are seats, luggage and combustible wall and ceiling panels. Only if the incipient fire reaches a certain size, can the spread to the neighbouring targets occur. In such cases, the fire transfers to local flashover but not until the gas temperature in the hot gas layer exceeds around $600{ }^{\circ} \mathrm{C}-800^{\circ} \mathrm{C}$. Then the fire starts to spread rapidly until finally the whole carriage becomes involved. At this point the fire becomes ventilation controlled and the size will be dictated by the number of openings.

The local flashover time in the 1:3 model scale tests 5 and 10 is shown in Fig. 4. Note that the only difference 
between these two tests was the number of open doors. The local flashover time for a given location is defined as the time when the local flashover occurs in this place based on a floor temperature of $600{ }^{\circ} \mathrm{C}$. As a comparison, the local flashover time based on a ceiling temperature of $600{ }^{\circ} \mathrm{C}$ is also presented. It is shown that the local flashover time based on floor and ceiling temperature correlate very well with each other. The time difference between the two methods is approximately constant, around $1.7 \mathrm{~min}$ in test 5 and $1.1 \mathrm{~min}$ in test 10. The corresponding time difference at full scale is $2.9 \mathrm{~min}$ and $1.9 \mathrm{~min}$. Comparing the two figures shows that the fire spread rate in Test 10 is much greater than in Test 5, due to more openings.
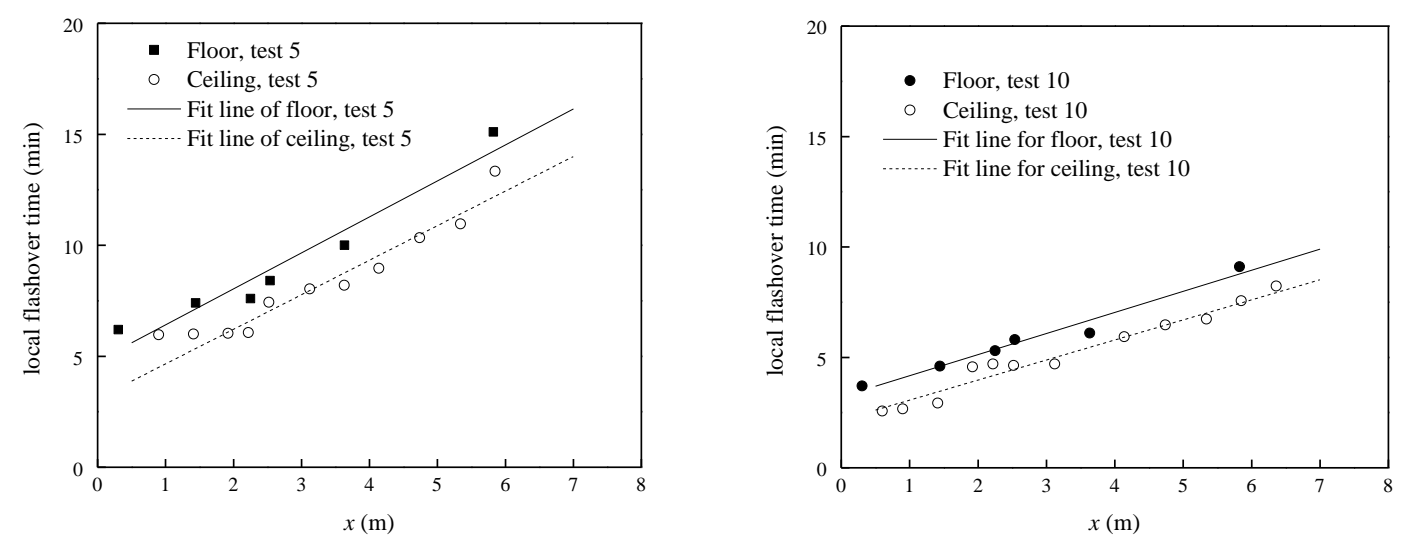

Fig. 4. The local flashover time in 1:3 model scale tests 5 (left) and 10 (right).

It is also shown in Fig. 4 that the average fire spread rate is close to a constant, that is, the fire travels along the carriage at an almost constant speed. This is not only due to the fire behavior of the individual material distributed along the carriage but also the configuration of the openings in the carriage. When the fire reached one opening, especially one door, part of heat was lost by convection and radiation. However, during this process, the smoke layer height beyond the local flashover region was always kept close to the upper edge of the doors, and more heat will be obtained from the combustion due to the fresh air flowing into the carriage. In short, although the evenly distributed openings increase the fire growth rate by supplying more oxygen and introducing an air flow, they also slow the fire growth by exhausting the hot flame and smoke flows. The overall effect of the openings is to increase the fire growth and also to keep the fire spread at a constant speed as observed from the tests data.

Fig. 5 shows the local flashover time in the full scale tests 2 and 3, respectively. Note that the main difference between these two tests was the interior lining materials. Similar trends can be found here. The fires in the carriages spread at an almost constant speed. Further, it can be seen that in test 2 the difference in the local flashover time based on the ceiling temperature and the floor temperature slightly increases with the travel distance, while the difference is almost a constant in test 3 . The slight difference could be due to the long period of the pre-heating in test 3 before the fire started to develop, which heated up the ceiling and wall temperatures and thus less response time was required for the increase of the ceiling temperature. Despite this, it is also shown in Fig. 5 that the local flashover time based on floor and ceiling temperature correlate well with each other. The average time difference between the two methods is approximately constant, around $1.85 \mathrm{~min}$ in test 2 and $1.9 \mathrm{~min}$ in test 3 . This suggests that the aluminum covering had an insignificant influence on the fire spread rate after the initial flame spread leading to the fire spread in the carriage. Comparing the average time difference of $1.875 \mathrm{~min}$ in full scale tests with the corresponding full-scale data of $2.9 \mathrm{~min}$ in $1: 3$ model test 5 and $1.9 \mathrm{~min}$ in test 10 suggests that the time difference scales relatively well and also it indicates that the 1:3 model test 10 correlate well with the full scale tests as explained earlier.

These figures indicate the average fire spread rate was $0.62 \mathrm{~m} / \mathrm{min}$ in 1:3 model scale test with 3 door open and $1.1 \mathrm{~m} / \mathrm{min}$ in 1:3 model scale test with 6 door open, according to the floor temperature. The corresponding values in full scale are around $1.1 \mathrm{~m} / \mathrm{min}$ and $1.8 \mathrm{~m} / \mathrm{min}$, respectively (using Equations (4)). Note that in the full scale tunnel fire tests, the average fire spread rate along the carriage was around 1.5 $\mathrm{m} / \mathrm{min}$ and $1.8 \mathrm{~m} / \mathrm{min}$. These values indicate that the full scale data correlate well with the 1:3 model scale tests with 6 doors open. Note that in the full scale tests, initially only three door on one side were open, 
however, all windows were broken up and all doors fell out during the tests. In other words, in full scale tests, the size of the openings is a time-dependent variable. This could explain why they correlate well with each other. The same reason could be responsible for the deviation of the data from model scale test 5 where only 3 doors were open.
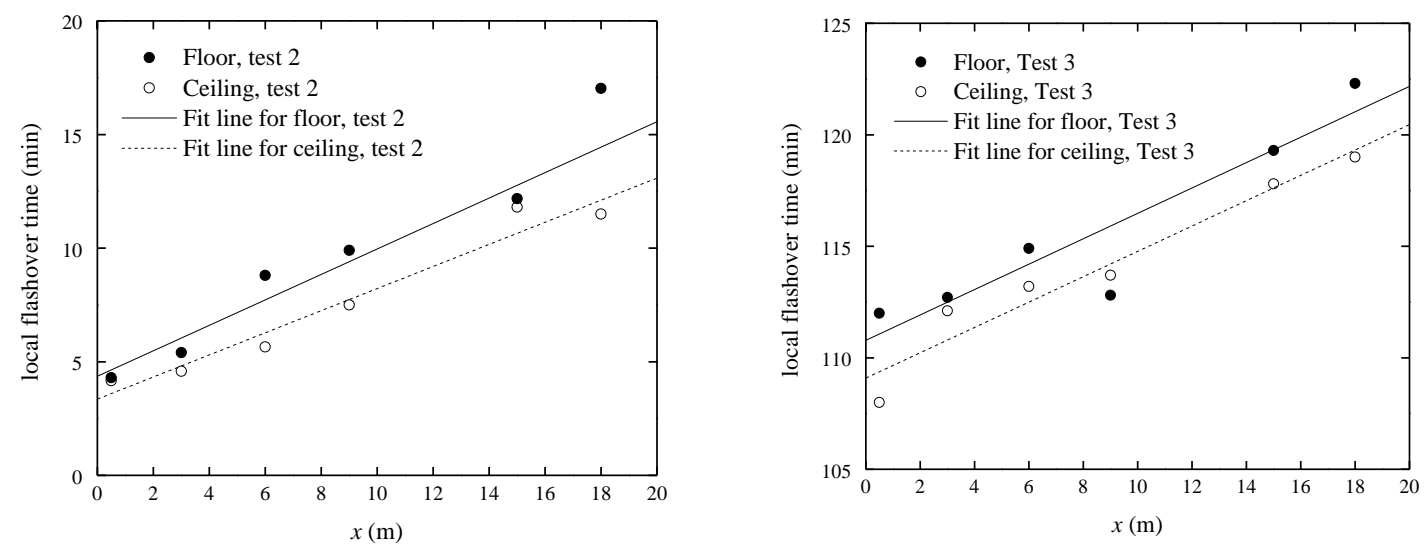

Fig. 5. The local flashover time in full scale Test 2 (left) and test 3 (right).

The above results show that, the fire grows more rapidly for a carriage with more openings, and the travelling time of the fire inside the carriage is shorter. In other words, the fire growth rate is greater if the carriage has more openings. This indicates the importance of the initial openings and the breakage of the openings during a carriage fire. This also depends on the relationship between the seat of the fire and the closest opening. The main reason for this is that in the growth period the fire is vitiated or locally under-ventilated in the area with closed windows and thus the increase of opening sizes increases the heat released inside the carriage as fresh air is introduced. The heat absorbed by the fuels inside the carriage is also increased at the same time.

The good correlation between different scales may also indicate that the influence of the tunnel and longitudinal flows in the full scale tests on the fire development of the carriages fires is limited as long as the fire is well ventilated. In other words, the heat release rate curve obtained from a carriage fire in the open and in the tunnel should be closely the same.

The ignition location has only a minor influence on the fire, but indeed a fire with ignition sources located in the middle of a carriage could reach its maximum heat release rate slightly earlier, based on the data from 1:3 model scale tests. However, it can be expected that the critical heat release rate required for the initial fire spread needs to be higher due to more entrainment of the fire plume compared to an initial fire at one end of the carriage.

\section{Maximum heat release rate}

The maximum heat release rates and the corresponding time in the tests involving fully developed fires in different scales are summarized in Table 3. The corresponding full-scale maximum heat release rates and the corresponding time are also presented for comparison.

It can be seen in Table 3 that the heat release rates in full scale range from $12 \mathrm{MW}$ to $77 \mathrm{MW}$, and the corresponding time ranges from $11 \mathrm{~min}$ to $118 \mathrm{~min}$. Despite the difference in the values, in reality good correlation can be found between the tests in different scales. In the full scale tests, the openings considered in the estimation of the maximum heat release rate consist of all the doors and windows which were either broken or fell out during the tests. It has to be pointed out that generally for a fully developed carriage fire, the openings available, including both the initial openings and the broken ones during a fire, dictates the level of the maximum heat release rate.

Comparing the 1:10 tests with the full scale test 2 shows that the maximum heat release rates in 1:10 model scale is slightly lower than the full scale data. The main reason is that in all the 1:10 model scale tests, only one door and 18 small windows were open and the total opening size is much smaller compared to the full scale train carriage used for other tests. However, comparing the correction factors estimated based on measured heat release rates, $\xi_{\text {meas }}$, in both series of tests show that the values correlate reasonably well. This 
suggests that the fire behavior inside the carriages were quite similar to each other, with the exception that the fuels inside the carriage in 1:10 model scale released more combustibles which resulted in a slightly higher correction factor. This was mainly due to the difficulties in finding the right materials fulfilling all the requirements according to the scaling theory. Further, comparing the corresponding time to reach maximum heat release rates shows that the time in 1:10 model scale correlates well with the full scale test 2, but not in full scale test 3 . This is due to the influence of aluminium linings in the train carriage in full scale test 3 which significantly delayed the time to flashover.

Table 3. Summary of heat release rates in different tests.

\begin{tabular}{|c|c|c|c|c|c|c|}
\hline \multirow{2}{*}{ Test series } & \multicolumn{2}{|c|}{$\begin{array}{c}\mathbf{H R R}_{\max } \\
(\mathbf{M W})\end{array}$} & \multicolumn{2}{c|}{$\begin{array}{c}\text { Time to HRR } \\
\text { (min) }\end{array}$} & $\begin{array}{c}\text { Measured } \\
\boldsymbol{\xi}_{\text {tot,meas }}\end{array}$ & $\begin{array}{c}\text { Calculated } \\
\boldsymbol{\xi}_{\text {tot,cal }}\end{array}$ \\
\hline & Model & Full & Model & Full & Eq. (20) & Eqs.(19) and (20) \\
\hline $1: 10$ plywood & $0.14-0.15$ & $43-47$ & $3.8^{\text {a }}$ & $11^{\text {a }}$ & $1.6-1.7$ & 1.65 \\
\hline $1: 10$ cardboard & $0.11-0.15$ & $36-45$ & $6.5^{\text {a }}$ & $15^{\text {a }}$ & $1.3-1.7$ & 1.48 \\
\hline $1: 3$ test 5 & 0.75 & 12 & 25.6 & 44 & 0.81 & 0.85 \\
\hline $1: 3$ test $10^{\mathrm{c}}$ & 1.24 & 19 & 38.3 & 66 & 0.67 & 0.85 \\
\hline Full scale test 2 & 76.7 & 76.7 & 12.7 & 12.7 & 1.26 & 1.26 \\
\hline Full scale test 3 & 77.4 & 77.4 & 118 & 118 & 1.27 & 1.26 \\
\hline
\end{tabular}

${ }^{a}$ corresponding to tests with all windows were initially open.

b 3 doors on one side were open and all windows closed.

${ }^{c} 6$ doors on both sides were open and all windows closed at ignition (six windows fell out, five before maximum HRR was reached).

Comparing the 1:3 model scale tests with the full scale tests shows that the maximum heat release rates in the $1: 3$ model scale is lower than the full scale data, and the corresponding time to maximum heat release rates is slightly longer than the full scale data. The main reason is that in the 1:3 model scale tests, the windows were all closed initially and also not broken up during the tests, except in test 10 when six windows fell out and two wooden window covers on the other side burnt through. In contrast, in the full scale tests, all the windows were broken (open) after the tests. In other words, the behaviour of windows breakage was not scaled in the tests. It has been shown previously that the openings increases the fire growth rate in the carriage fires and also the maximum heat release rate in fully developed fires. Further, the fuels were not perfectly scaled down due to the difficulty in finding materials that scales perfectly.

\section{The correction factor for HRR}

When a carriage fire becomes fully developed, the fire tends to be ventilation controlled due to limited openings. The maximum heat release rate in these tests generally can be estimated based on the fully consumption of the oxygen flowing into through the openings multiplying by the correction factor of the heat release rate, $\xi$, which is shown in Table $3 . \xi_{\text {meas }}$ is obtained by Eq. (20) using the measured heat release rate, and $\xi_{c a l}$ is calculated using the proposed equations (19) and (20). Clearly, it shows that the correction factor ranges from 0.67 to 1.7 and is around 1.27 in the full scale tests. The estimated correction factor using Eq. (19) and Eq. (20) correlates well with the tests data, which validates the simple model and also proves that the assumed heat fraction of 0.23 is reasonable for these types of carriage fires.

Table 4 shows the detailed data to estimate the correction factors in different scales of carriage fire tests. The parameters in the table are mostly obtained from the lab test, except the data of the heat of pyrolysis that are obtained from SFPE handbook [16] and Drysdale's book [17]. Further, the heat of pyrolysis for the laminate boards on the walls in the full scale tests and for the corrugated cardboard in 1:10 model scale tests, are estimated based on similar materials, i.e. plywood. Note that the energy balance at the surface:

$$
\dot{m}_{f}^{\prime \prime} L_{p}=\dot{q}_{e}^{\prime \prime}+\chi_{r} \dot{m}_{f}^{\prime \prime} \Delta H_{c}-\dot{q}_{l o s s}^{\prime \prime}
$$

where $\dot{q}_{e}^{\prime \prime}$ is the absorbed external heat flux by the surface, and $\dot{q}_{l o s s}^{\prime \prime}$ is the heat loss at the surface. For similar fuels, the ignition temperatures, and soot yields could be very similar to each other. This could result in a similarity in the heat gained from the flame by convection and radiation heat transfer which should be close 
to each other. As a rough estimation, the heat of pyrolysis for similar materials, therefore, could be approximately estimated by:

$$
L_{p 1} \approx \frac{\dot{m}_{f 2}^{\prime \prime}}{\dot{m}_{f 1}^{\prime \prime}} L_{p 2}
$$

In Table 4, the fuels are identified and then the exposed fuel surfaces for each fuel type are estimated for each test. Then the fraction of heat absorbed by the $i$ th fuel surfaces, $\chi_{r, i}$, is estimated using Eq. (16), and finally the correction factor can be calculated using Eq. (19) and Eq. (20). Note that for 1:3 model scale tests, the wood cribs are intensely placed at the floor level, however, these surfaces cannot absorb equivalent heat compared to the seat surfaces or wall surfaces. Therefore, the external surface area of the "virtual wood box" are used in estimation of the fraction $\chi_{r, i}$. Besides, all the realistic exposed fuel surfaces are used for estimation. Note that the fraction of heat absorbed by all surfaces, $\chi_{r}$, in Eq. (16) was pre-determined as 0.23 , which has been proven to be very reasonable.

Table 4. Parameters to estimate the correction factor.

\begin{tabular}{|c|c|c|c|c|c|}
\hline Test series & Fuels compositions & $\begin{array}{c}\text { Fraction } \\
A_{i} / A_{t} \\
\end{array}$ & $\Delta H_{c}$ & $L_{p}$ & $\begin{array}{c}\xi_{t o t, c a l} \\
\text { Eqs. (19) and (20) }\end{array}$ \\
\hline & & & $\mathrm{MJ} / \mathrm{kg}$ & $\mathrm{MJ} / \mathrm{kg}$ & \\
\hline \multirow{4}{*}{ Full scale tests } & Plywood & $21 \%$ & 12.8 & 0.95 & \multirow{4}{*}{1.26} \\
\hline & Laminate & $57 \%$ & 7.6 & $2.01^{*}$ & \\
\hline & Seat PUR & $11 \%$ & 25.3 & 1.22 & \\
\hline & Luggage $^{* *}$ & $11 \%$ & 21.4 & 1.63 & \\
\hline \multirow{4}{*}{$1: 3$ model scale } & Plywood & $15 \%$ & 12.8 & 0.95 & \multirow{4}{*}{0.85} \\
\hline & Laminate & $42 \%$ & 7.2 & $1.90^{*}$ & \\
\hline & Seat PUR & $8 \%$ & 25.3 & 1.22 & \\
\hline & Wood crib & $9 \%$ & 16.7 & 2.64 & \\
\hline \multirow[t]{2}{*}{ 1: 10 \# Fuel 1} & Plywood & $89 \%$ & 11.6 & 0.95 & \multirow{2}{*}{1.65} \\
\hline & Wood crib & $11 \%$ & 16.7 & 2.64 & \\
\hline \multirow[t]{2}{*}{ 1: 10 \# Fuel 2} & corrugated cardboard & $89 \%$ & 16.3 & $1.49^{*}$ & \multirow{2}{*}{1.48} \\
\hline & Wood crib & $11 \%$ & 16.7 & 2.64 & \\
\hline
\end{tabular}

"estimated using the proposed simple equation Eq. (22).

** $60 \%$ plastic and $40 \%$ cellulosic materials.

For a ventilation controlled fire, a large portion of heat will be released outside the carriage. As discussed earlier, the correction factor of the maximum heat release rate, $\xi$, in a fully developed fire is mainly dependent on the heat absorbed by the fuels inside the carriage since a typical train generally has potential fuels to produce an even higher heat release rate. Therefore, the coefficient, $\xi$, is mainly dependent on properties and configuration of the fuels. A larger opening supports a higher heat release rate which in turn results in a higher fuel mass burning rate. The maximum heat release rate is a value in the equilibrium of the heat balance.

Note that in carriages, fire retardant materials are commonly used as interior materials. The influence of fire retardant materials on the fire development in a train carriage is not discussed here.

\section{CONCLUSIONS}

The fire development and HRR in three series of train carriage fire tests in different scales were analyzed. These carriage fire tests included 1:10 model scale tests, 1:3 model scale tests and 1:1 full scale tunnel tests. The mechanisms of fire development were very similar in all the tests. After the critical fire spread, a local flashover occurred and the whole section became involved. Thereafter, the fire spread along the carriage until finally the whole carriage was involved in the combustion. In other words, the fire behaves as a travelling fire. At this stage, the radiation from the ceiling flame and smoke to the lower targets is considered to be the main 
mode of fire spread in a carriage. The equivalent parameter could be a critical gas temperature in the ceiling gas layer around $600{ }^{\circ} \mathrm{C}-800{ }^{\circ} \mathrm{C}$. The average fire spread rate along the carriage was nearly constant, i.e., the fire traveled along the carriage at an approximately constant speed. The average fire spread rate was around $1.5 \mathrm{~m} / \mathrm{min}$ and $1.8 \mathrm{~m} / \mathrm{min}$ in full scale tests 2 and 3 respectively, and the full-scale fire spread rate in the $1: 3$ model scale tests was $1.1 \mathrm{~m} / \mathrm{min}$ with 3 doors open and $1.8 \mathrm{~m} / \mathrm{min}$ with 6 doors open, respectively. Since all the doors in the carriage fell out during the full scale tests, the 1:3 model scale test with 6 doors open was most similar to the full scale tests and thus good agreement can be found.

A fully developed carriage fire could be either fuel controlled or ventilation controlled. A simple equation, Eq. (19), has been proposed to estimate the maximum heat release rate in a fully developed carriage fire, for both ventilation controlled and fuel controlled fires. The equation has been proved to be able to correlate all the tests data in different scales very well. It has to be pointed out that generally for a fully developed carriage fire, the openings available, including both the initial openings and the broken ones during a fire, dictate the level of the maximum heat release rate. These fires generally involved enough fuels to burn and thus were ventilation controlled. Therefore, the maximum heat release rate in these tests can be estimated based on full consumption of the oxygen flowing in through the openings multiplying by a correction factor, which depends on the heat absorbed by the fuel surfaces and the fuels available. The heat absorbed by the surfaces was proportional to the heat of combustion and inversely proportional to the heat of pyrolysis. In addition, the fraction of the fuel surfaces exposed to the fire also has a strong influence on the maximum heat release rate. The global correction factor was around 1.26 in full scale tests, 1.3 to 1.7 in 1:10 model scale tests and 0.67 to 0.8 in 1:3 model scale tests, which correlate well with the proposed equation.

\section{REFERENCES}

[1] Ingason, H., Kumm, M., Nilsson, D., Lönnermark, A., Claesson, A., Li, Y. Z., Fridolf, K., Åkerstedt, R., Nyman, H., Dittmer, T., Forsén, R., Janzon, B., Meyer, G., Bryntse, A., Carlberg, T., Newlove-Eriksson, L. and Palm A., The METRO project - Final report, School of Sustainable Development of Society and Technology, Mälardalen University, SiST Research report 2012:8, Västerås, Sweden, 2012, 115 p.

[2] Ingason, H., (2007) Model scale railcar fire tests, Fire Safety Journal 42: 271-282, http://dx.doi.org/10.1016/j.firesaf.2006.11.004

[3] Lönnermark, A., Lindström, J. and Li, Y.Z., Model-scale metro car fire tests, SP Technical Research Institute of Sweden SP Report 2011:33, Borås, Sweden, 2011, 115 p.

[4] Claesson, A., Lönnermark, A., Ingason, H., Lindström J., Li, Y.Z., and Kumm, M., Laboratory fire experiments with a 1/3 train carriage mockup, SP Technical Research Institute of Sweden SP Report 2012:06, Borås, Sweden, 2012, 74 p.

[5] Lönnermark, A., Lindström, J., Li, Y.Z., Claesson, A., Ingason, H., and Kumm, M., Full-scale fire tests with a commuter train in a tunnel, SP Technical Research Institute of Sweden SP Report 2012:05, Borås, Sweden, 2012, 150 p.

[6] Lönnermark, A., Lindström, J., Li, Y.Z., Ingason, H., and Kumm, M., "Large-scale commuter train fire tests - Results from the METRO project", Proceedings from the Fifth International Symposium on Tunnel Safety and Security, New York, 2012, pp. 447-456.

[7] Li, Y.Z., Lei, B., and Ingason, H., (2011) The maximum temperature of buoyancy-driven smoke flow beneath the ceiling in tunnel fires, Fire Safety Journal 46: 204-210, http://dx.doi.org/10.1016/j.firesaf.2011.02.002

[8] Li, Y.Z. and Ingason, H., (2012) The maximum ceiling gas temperature in a large tunnel fire, Fire Safety Journal 48: 38-48, http://dx.doi.org/10.1016/j.firesaf.2011.12.011

[9] Li, Y.Z., Lei, B. and Ingason, H., (2010) Study of critical velocity and backlayering length in longitudinally ventilated tunnel fires, Fire Safety Journal 45: 361-370, http://dx.doi.org/10.1016/j.firesaf.2010.07.003.

[10] Li, Y.Z., Lei, B. and Ingason, H., (2013) Theoretical and experimental study of critical velocity for smoke control in a tunnel cross-passage, Fire Technology 49(2): 435-449, 
[11] Li, Y.Z., Lei, B. and Ingason, H., (2012) Scale Modeling and Numerical Simulation of Smoke Control for Rescue Stations in Long Railway Tunnels, Journal of Fire Protection Engineering 22(2): 101-131, http://dx.doi.org/10.1177/1042391512445409

[12] Ingason, H. and Li, Y.Z., (2010) Model scale tunnel fire tests with longitudinal ventilation, Fire Safety Journal 45:371-384, http://dx.doi.org/10.1016/j.firesaf.2010.07.004

[13] Ingason, H. and Li, Y.Z., (2011) Model scale tunnel fire tests with point extraction ventilation, Journal of Fire Protection Engineering 21(1): 5-36, http://dx.doi.org/10.1177/1042391510394242

[14] Li, Y.Z. and Ingason, H., The fire growth rate in a ventilated tunnel fire, Fire Safety Science Proceedings of the Tenth International Symposium, International Association for Fire Safety Science, 2011, pp. 347-358, http://dx.doi.org/10.3801/IAFSS.FSS.10-347

[15] Li, Y.Z. and Ingason, H., (2012) Position of maximum ceiling temperature in a tunnel fire, Fire Technology, http://dx.doi.org/10.1007/s10694-012-0309-2

[16] DiNenno, P.J. (ed.), The SFPE Handbook of Fire Protection Engineering (3rd ed), National Fire Protection Association, Quincy, MA, 2002.

[17] Drysdale, D., An Introduction to Fire Dynamics (2nd ed), John Wiley \& Sons, Chichester, 1999. 